\title{
Controlling of disease causing pathogens using silver nanoparticles synthesized by one step green procedure
}

\author{
S. Venkat Kumar ${ }^{1}$, S. Karpagambigai ${ }^{2}$, P. Jacquline Rosy ${ }^{3}$, S. Rajeshkumar ${ }^{1 *}$ \\ ${ }^{1}$ School of Bio-Sciences and Technology, VIT University, Vellore - 632014, TN, India. \\ ${ }^{2}$ Departmant of Chemistry, Global Institute of Engineering and Technology, Vellore -632509, TN, India. \\ ${ }^{3}$ Department of Chemistry, IFET College of Engineering, Villupuram-605108, TN, India.
}

\begin{tabular}{|c|}
\hline ARTICLE INFO \\
\hline Article history: \\
\hline Received on: $18 / 04 / 2017$ \\
\hline Accepted on: $21 / 08 / 2017$ \\
\hline Available online: $28 / 01 / 2018$ \\
\hline Key words: \\
\hline $\begin{array}{l}\text { Biosynthesis; silver } \\
\text { nanoparticles; antibacterial } \\
\text { activity; SEM; XRD. }\end{array}$ \\
\hline
\end{tabular}

activity; SEM; XRD

\begin{abstract}
Biosynthesis of nanoparticles is the important area in applicable nanoparticles and development of nanobiotechnology. In this present investigation, we used soil bacteria Proteus sp for the biosynthesis of silver nanoparticles. The synthesized nanoparticles were visually observed and characterized using UV-vis spectrophotometer for its surface plasmn resonance, crystalline nature was identified by X-ray diffraction assay and morphology was identified using scanning electron microscope. The peak at $430 \mathrm{~nm}$ in UV-vis spectroscopy confirms the SPR and XRD shows the intensity of (lllll $\left.\begin{array}{lll}1 & 1 & 1\end{array}\right)$ and $\left(\begin{array}{lll}2 & 2 & 2\end{array}\right)$ confirm the crystalline nature. The 50-100 $\mathrm{nm}$ sized and spherical shaped nanoparticles are synthesized was confirmed by SEM. The antibacterial activity of the silver nanoparticles analysed using agar well diffusion method, shows very good zone of inhibition equals to commercially available antibiotics.
\end{abstract}

\section{INTRODUCTION}

Biosynthesis of nanoparticles is the emerging field in nanoscience and nanotechnology. Using of biological entities such as bacteria, fungus, yeast, actinomycetes, plants and algae for the synthesis of silver nanoparticles have been developed. The bacterial isolates such as Marine bacteria Enterococcus sp. (Rajeshkumar et al., 2016), extremophilic Ureibacillus thermosphaericus (Juibari et al. 2011), Gluconobacter roseus (Krishnaraj and Berchmans, 2013), Vibrio alginolyticus (Rajeshkumar et al., 2013), Pseudomonas aeruginosa (Kumar and Mamidyala 2011), Bacillus sp. (Malarkodi et al., 2013), Bacillus licheniformis (Kalimuthu et al., 2008), Enterobacter aerogenes (Karthik and Radha, 2012), Streptomyces sp. LK3 (Karthik et al., 2014), Escherichia coli ATCC 8739, Bacillus subtilis ATCC 6633, and Streptococcus thermophiles ESh1

\footnotetext{
* Corresponding Author

Dr. S. Rajeshkumar, Research Scientist School of Bio-Sciences and Technology, VIT University, Vellore - 632014, TN, India.

Email: ssrajeshkumar@hotmail.com
}

(El- Shanshoury et al., 2011), Serratia nematodiphila (Malarkodi et al., 2013), Bacillus subtilis MTCC 3053 (Paulkumar et al., 2013), Acinetobacter calcoaceticus (Gaidhani et al., 2013), Salmonella typhirium (Ghorbani, 2013) Brevibacterium casei (Kalishwaralal et al., 2010), thermophilic bacterium Geobacillus stearothermophilus (Fayaz et al., 2011). Silver nanoparticles are having wide range of applications in biomedical arena such as antibacterial activity against both gram positive and gram negative bacterial isolates (Rajeshkumar, 2016) and food borne pathogens (Rajeshkumar and Malarkodi, 2014), antifungal activity against Aspergillus niger, Aspergillus fumigatus, Candida albicans, Aspergillus flavus and Fusarium sp (Rajeshkumar et al., 2014), anticancer activity against liver and lung cancer lines, enhanced antibacterial (increasing of antibiotics sensitivity by coating of silver nanopartilces with different antibiotics disc such as Ampicillin, Tetracycline, Novabiocin, Penicillin, anamycin, Gendamycin, Chloramphenicol, Streptomycin and Ciprofloxacin) effect (Rajeshkumar et al., 2016). Catalysis (Jiang et al., 2005), biosensors for antigen and antibody binding (Zhu et al., 2009), controls the growth the dermatophytes, antiviral activity against 
human immuno deficiency, virus, Molecular imaging of cancer cells, wound healing properties (Caro et al., 2010). In this present investigation we used Proteus sp isolated from soil sample for the synthesis of silver nanoparticles and it was characterized using UV-vis spectrophotometer, Scanning electron microscope, elemental analysis, X-ray diffraction assay. The antibacterial activity of silver nanoparticles against Staphylococcus aureus, Escherichia coli, Bacillus sp, Salmonella sp, pseudomonas areogenusa and Klebsiella pneumoniae was performed.

\section{MATERIALS AND METHODS}

\section{Isolation and Identification of bacteria}

$1 \mathrm{~g}$ soil sample was added into $100 \mathrm{ml}$ sterile distilled water and agitated for uniform microbial suspension. Serial dilutions were performed by decimal dilutions made up to $10^{-7}$. From these dilutions $1 \mathrm{ml}$ aliquots were poured into sterile petriplates containing Nutrient Agar medium (Hi - media, Mumbai, India).

Plates were incubated at $37{ }^{\circ} \mathrm{C}$ for $24-48$ hours. The individual colonies were isolated by streaking on nutrient agar plates and incubated at $37{ }^{\circ} \mathrm{C}$ for $24 \mathrm{hrs}$ and the bacteria were identified based on morphological structure. The morphological and physiological characterization of the isolate was performed according to the methods described in Bergey's Manual of determinative bacteriology.

\section{Synthesis and characterization of silver nanoparticles}

In extracellular synthesis process, the culture supernatant of Proteus sp was used. The culture was grown in nutrient broth. Proteus sp was grown in $250 \mathrm{ml}$ conical flask containing $100 \mathrm{ml}$ of sterile nutrient broth for 24 hours at $37{ }^{\circ} \mathrm{C}$ in rotary shaker at 220 rpm. After the incubation the culture was centrifuged at 10,000 rpm for 10 minutes and collects the supernatant. To this supernatant $1 \mathrm{mM}$ of silver nitrate was added and change of colour was noted at $24 \mathrm{~h}$ of incubation.

The change of colour was indicates the formation of silver nanoparticles and periodically analysed by UV-vis Spectrophotometer at different wavelength. The silver nanoparticles powder was prepared using centrifugation and it was washed 3 times using double distilled water. Finally the collected pellets was collected in the petri-plates and kept in hot air oven for $80{ }^{\circ} \mathrm{C}$. The nanoparticles powder was characterized using SEM, EDX and XRD.

\section{Antibacterial activity}

Luria Bertani Agar medium was used to cultivate bacteria. Fresh overnight culture of each strain was swabbed uniformly onto the individuals plates using sterile cotton swabs. 3 wells were made on each Luria Bertani Agar plates. Then the centrifuged silver nanoparticles $(25 \mu 1,50 \mu \mathrm{l}$ and $75 \mu \mathrm{l})$ were poured into each well on all plates and incubate for $24 \mathrm{hrs}$ at 37 ${ }^{\circ} \mathrm{C}$. After incubation the different levels of zonation formed around the well was measured.

\section{RESULTS AND DISCUSSION}

Synthesis of silver nanoparticles using Proteus sp.,

Extracellular synthesis of silver nanoparticles using Proteus sp was primarily identified by visual identification, appearance of whitish brown colour in the reaction mixture indicates the formation of nanoparticles (Fig 1). The bacterial biomass of culture shows pale yellow in colour before the addition of silver nitrate and this changed into light brown colour. The colour was formed after the $12 \mathrm{~h}$ of incubation indicating the rapid preparation of silver nanoparticles. After $48 \mathrm{~h}$ of incubation the reaction mixture shows brownish colour indicating the completion of reaction. The formation of brownish colour in bacterial biomass indicates the silver nanoparticles (Rajeshkumar et al., 2016).

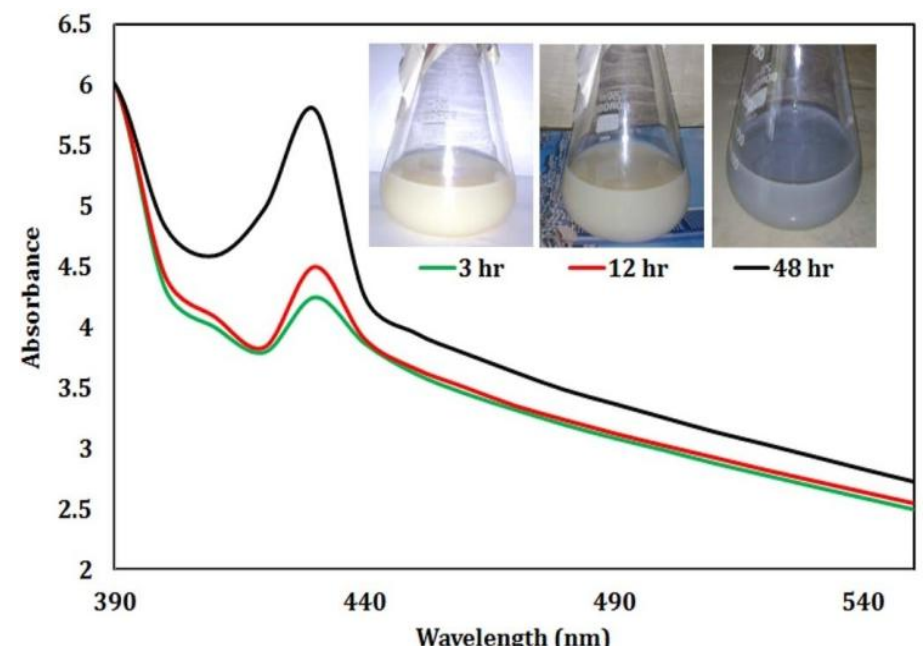

Fig. 1: UV-vis absorbance and visual observation of biosynthesis of silver nanoparticles using Proteus sp.

Fig. 1 shows the UV spectrum recorded as synthesized silver nanoparticles at different functional time. Paulkumar et al., 2014 reported that UV-vis Spectroscopy is a very useful technique to characterize the silver nanoparticles synthesis. The culture supernatant of Proteus sp., was collected at the stationary phase for extreme nanoparticles biosynthesis. UV- vis spectrophotometer shows that the silver nanoparticle synthesis after the adding of silver nitrate into the bacterial culture at the growth phase, the absorption band was formed at $430 \mathrm{~nm}$ at the incubation time of 3 $h$ with small peak indicates the formation of small size of nanoparticles. After the $12 \mathrm{~h}$ of incubation the absorption peak was shift into $429 \mathrm{~nm}$ due to the excitation of surface plasmon resonance of the nanoparticles. The alterations in the position of surface plasmon resonance band due to the development of differences in the shape or size of nanoparticles by the biogroups of Serratia nematodiphila and Bacillus subtilis (Malarkodi et al 2014; Paulkumar et al 2014). We recorded the absorbance on $48 \mathrm{hr}$ shows peak at $430 \mathrm{~nm}$ indicates the stability of the nanoparticles. 


\section{X-Ray Diffraction assay}

Fig 2 shows the XRD spectrum of bio synthesized silver nanoparticles using culture supernatant of Proteus $s p$. The XRD pattern showed the whole spectrum of 2 theta scale ranges from 10-80. The two intense peaks showed at 2 theta scale values of $38.0^{\circ}$ and $44.0^{\circ}$ corresponding to the planes of (lllll) and $\left.1 \begin{array}{lll}2 & 2 & 2\end{array}\right)$ for fcc of silver. The strong peak at $38.0^{\circ}$ and $44.0^{\circ}$ is ascribed of face-centered cubic silver structure, while other diffraction peak shows much weak. The sharpening of the peaks evidently indicates that the particles are in the size of nano (Amin et al. 2013, Penga et al., 2013). The weak peaks are due to the organic moiety present in the bacterial culture (Pourali, and Yahyaei, 2016).

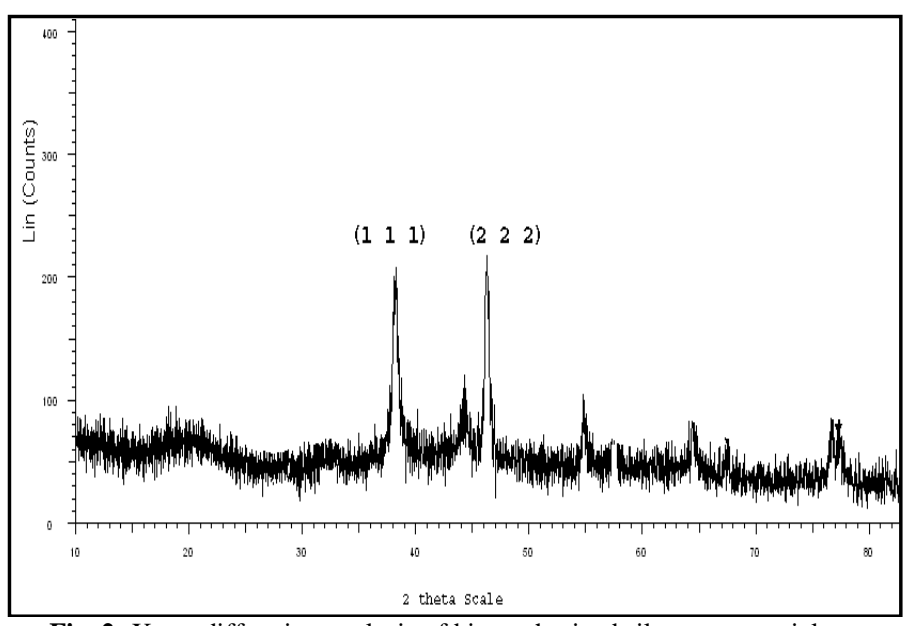

Fig. 2: X-ray diffraction analysis of biosynthesized silver nanoparticles.

\section{Scanning electron microscope}

Morphological characterization of silver nanoparticles synthesized by using Proteus sp was analysed using SEM shown in fig 3. The nanoparticles show undefined spherical and rectangle shape with high agglomeration. The size of the nanoparticles ranges from 50-100 nm magnifications. Agglomeration found due to higher proportion of capping agent in the bacterial biomass. The reduced amount of organic moieties also responsible for the agglomeration of nanoparticles (Paulkumar et al., 2014).

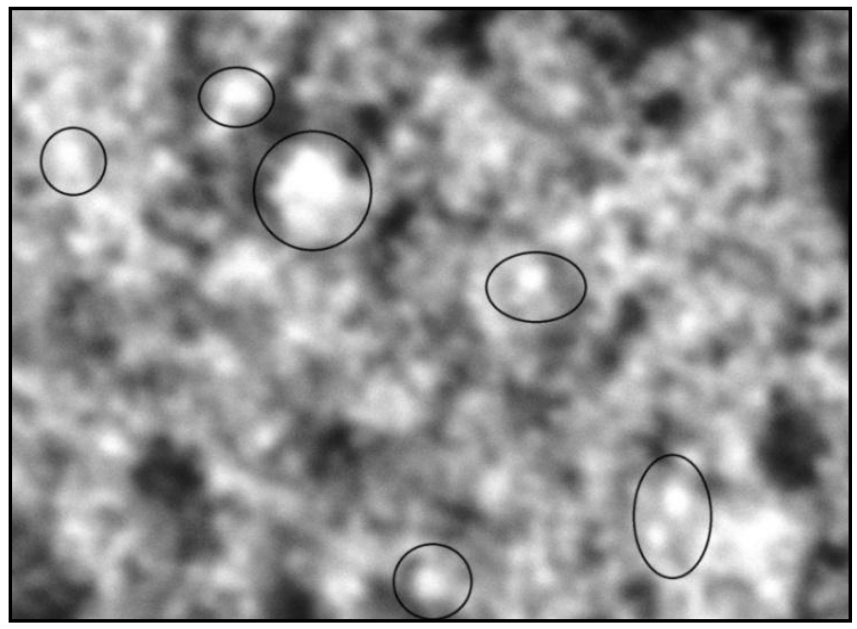

Fig. 3: SEM image of silver nanoparticles synthesized using Proteus sp.

\section{Energy dispersive X-ray spectroscopy}

Analysis using Energy dispersive X-ray (EDX) spectrometer confirms the presence of elemental silver signal of the silver nanoparticles (Fig 4). Documentation lines for the major emission energies for silver (Ag) are displayed and these are similar to with peaks at $3 \mathrm{keV}$ in the spectrum, thus giving confidence that silver has been correctly identified. EDX analysis confirmed the elements were $\mathrm{Ag}$ and $\mathrm{O}$ and the weight percentage were $63.70 \%$ and $36.30 \%$ respectively. Some of the weak peaks also observed in EDX are formed due to X-ray emission from various organic moieties present within the bacterial culture.

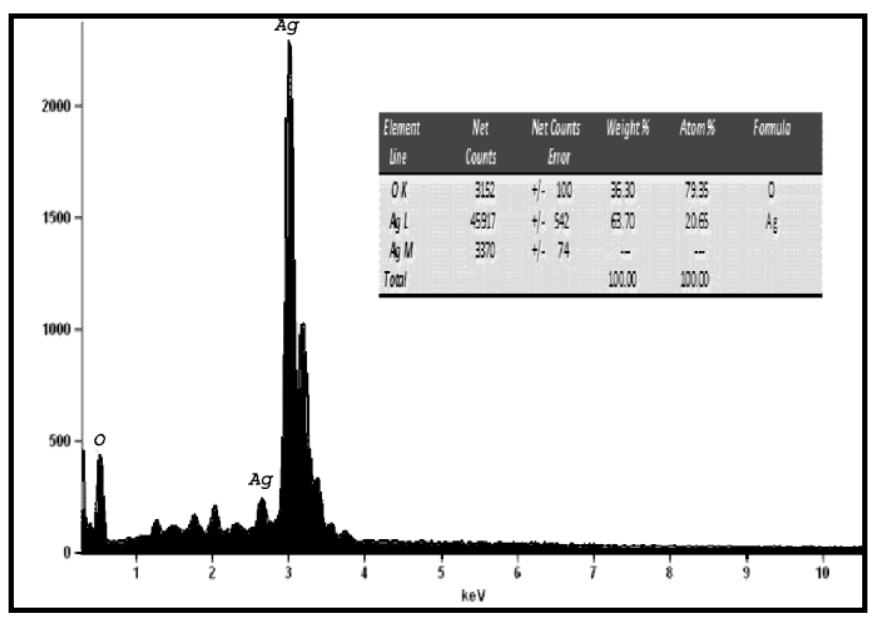

Fig. 4: EDX spectrum of silver nanoparticles synthesized from Proteus sp.

\section{Antibacterial activity of nanoparticles}

Antibacterial activity of silver nanoparticles against gram positive bacteria like Bacillus sp and Staphylococcus aureus and gram negative isolates such as Salmonella sp, Pseudomonas aeruginosa, Klebsiella pneumoniae and E.coli performed by agar well diffusion method. The bacterial cultures we used are mostly disease causing pathogens like Salmonella is causative agent for typhoid fever, E.coli and S. aureus are food borne pathogens and other bacterial strains are responsible so many infections to plants and humans. The silver nanoparticles are sensitive against all the pathogens, in that when compare to gram positive gram negative bacteria have better zone of inhibition (Fig $5 \& 6$ ).

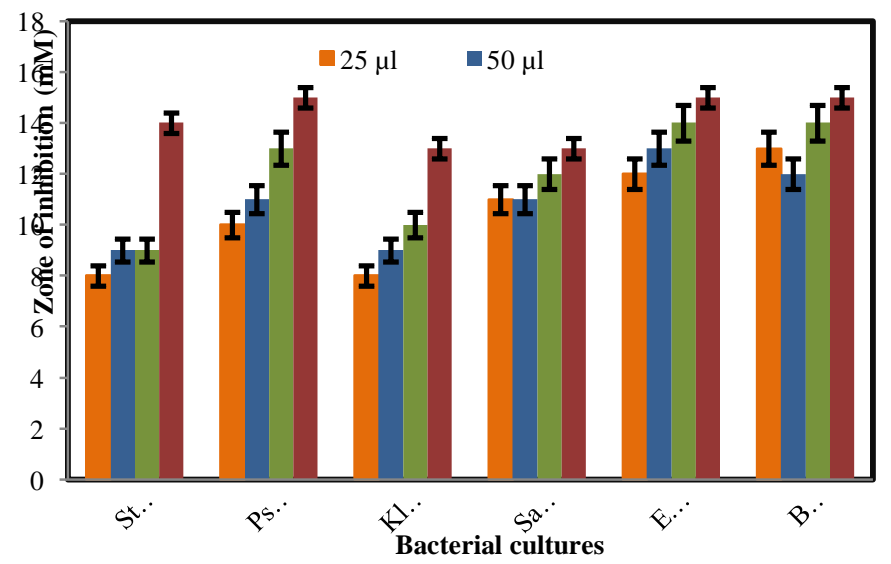

Fig. 5: Clustered column chart of antimicrobial activity of silver nanoparticles. 
Among the four gram negative pathogens the silver nanoparticles very effectively work against Pseudomonas aeruginosa is a multidrug resistant pathogen. Silver nanoparticles may disturb the cell wall of the bacteria and involved in the process of inhibition of DNA replication is major reason for controlling of bacterial growth (Rajeshkumar, 2016).
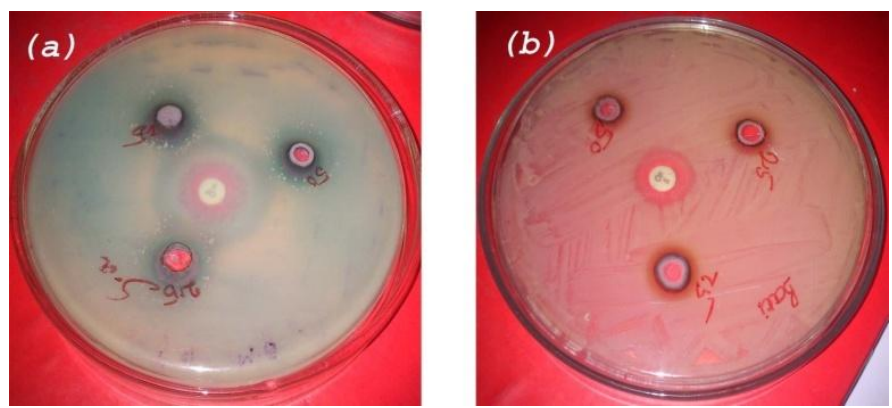

Fig. 6: Antimicrobial activity of silver nanoparticles against gram positive bacteria (a) Staphylococcus aureus and (b) Bacillus sp.
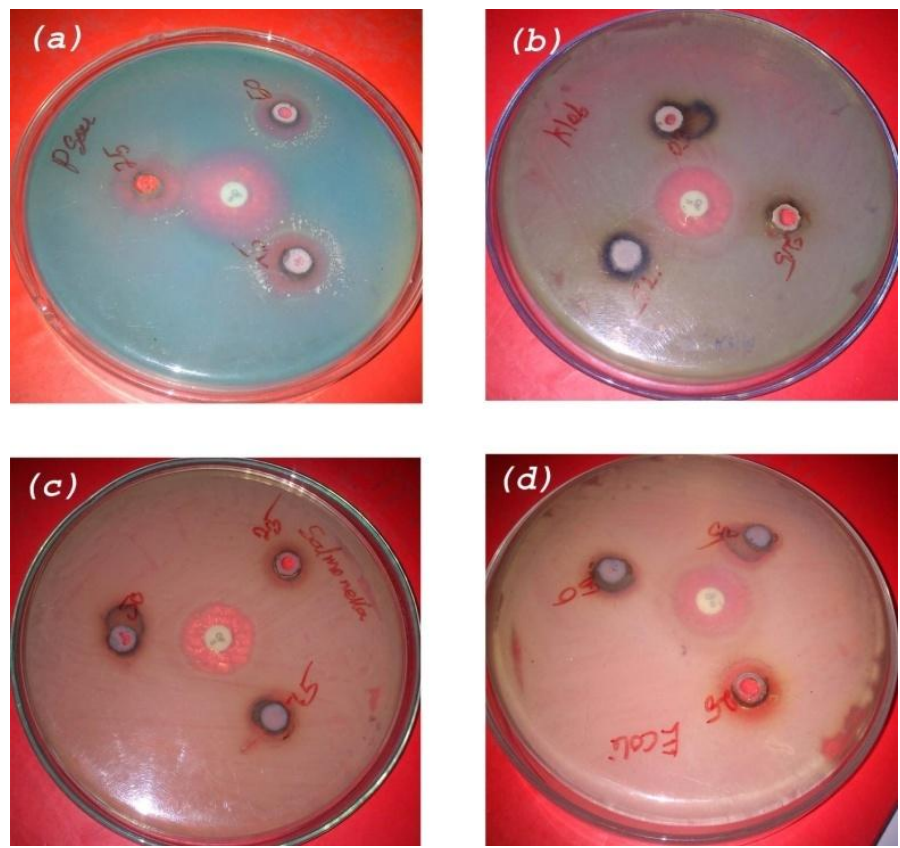

Fig. 7: Antimicrobial activity of silver nanoparticles against gram negative bacteria (a) Pseudomonas aeruginosa (b) Klebsiella pneumoniae (c) Salmonella sp and (d) E.coli.

\section{CONCLUSION}

In this present study we used proteus $s p$ a soil bacteria for the synthesis of silver nanoparticles using one step synthesis. The results of UV-vis spectroscopy, XRD, SEM and EDX are confirm the surface plasmon resonance, very good crystalline nature, spherical shape and elements of bacterial meditaed synthesis of silver nanoparticles. The stability of the nanoparticles is good was confirmed by UV-vis spectroscopic analysis. The silver nanoparticles have good growth control of some disease causing pathogens may responsible for food poisoning, typhoid fever, pneumonia fever and etc. Based on our results, it is possible to produce pharmaceutical agents and drugs for the above mentioned health problems.

\section{CONFLICT OF INTEREST}

The authors declare no conflict of interest.

\section{REFERENCE}

Amin M, Iram F, Iqbal M S., Saeed M Z., Razaa M, Alame S Arabinoxylan-mediated synthesis of gold and silver nanoparticles having exceptional high stability Carbohydrate Polymers, 2013; 92: 18961900

Caro C, Castillo PM, Klippstein R, et al. 2010. Silver nanoparticles: sensing and imaging applications. In: Perez DP, ed. Silver nanoparticles. Rijeka, Croatia: InTech, 201-24.

El-Shanshoury AER, ElSilk SE, Ebeid ME. Extracellular biosynthesis of silver nanoparticles using Escherichia coli ATCC 8739, Bacillus subtilis ATCC 6633, and Streptococcus thermophiles ESh1 and their antimicrobial activities. ISRN Nanotechnol. 2011; doi: $10.5402 / 2011 / 385480$

Fayaz AM, GirilalM, RahmanM, Venkatesan R,Kalaichelvan PT. Biosynthesis of silver and gold nanoparticles using thermophilic bacterium Geobacillus stearothermophilus. Process Biochem, 2011; 46: $1958-1962$.

Gaidhani S, Singh R, Singh D, Patel U, Shevade K, Yeshvekar R, Chopade BA. Biofilm disruption activity of silver nanoparticles synthesized by Acinetobacter calcoaceticus PUCM 1005. Mater Lett 2013; 108:324-327

Ghorbani HR. Biosynthesis of silver nanoparticles using Salmonella typhirium. J Nanostruct Chem , 2013; 3:29-32.

Jiang Z-J, Liu C-Y, Sun L-W. Catalytic properties of silver nanoparticles supported on silica spheres. J Phys Chem B, 2005; 109:1730-5.

Juibari MM, Abbasalizadeh S, Jouzani GS, Noruzi M. Intensified biosynthesis of silver nanoparticles using a native extremophilic Ureibacillus thermosphaericus strain. Mater Lett, 2011; 65: 1014-1017

Kalimuthu K, Suresh Babu R, Venkataraman D, Bilal M, Gurunathan S. Biosynthesis of silver nanocrystals by Bacillus licheniformis. Colloids Surf B Biointerfaces, 2008; 65:150-153.

Kalishwaralal K, Deepak V, Pandian SRK, Kottaisamy M, BarathManiKanth S, Kartikeyan B, Gurunathan S. Biosynthesis of silver and gold nanoparticles using Brevibacterium casei. Colloids Surf B Biointerfaces, 2010; 77:257-262.

Karthik C, Radha KV. Biosynthesis and characterization of silver nanoparticles using Enterobacter aerogenes: a kinetic approach. Dig J Nanomater Biostruct, 2012; 7:1007-1014.

Karthik L, Kumar G, Kirthi AV, Rahuman AA, Rao KVB. Streptomyces sp. LK3 mediated synthesis of silver nanoparticles and its biomedical application. Bioprocess Biosyst Eng, 2014; 37:261-267

Krishnaraj RN, Berchmans S. In vitro antiplatelet activity of silver nanoparticles synthesized using the microorganism Gluconobacter roseus: an AFM-based study. RSC Adv, 2013; 3:8953-8959

Kumar CG, Mamidyala SK. Extracellular synthesis of silver nanoparticles using culture supernatant of Pseudomonas aeruginosa. Colloids Surf B Biointerfaces, 2011; 84:462-466.

Malarkodi C, Rajeshkumar S, Paulkumar K, Gnanajobitha G, Vanaja M, G Annadurai Bacterial synthesis of silver nanoparticles by using optimized biomass growth of Bacillus sp. Nanoscience and nanotechnology - An international Journal 2013; 3(2): 26-32.

Malarkodi C, Rajeshkumar S, K Paulkumar, M Vanaja M, G GnanaJobitha, G Annadurai Bactericidal activity of bio mediated silver nanoparticles synthesized by Serratia nematodiphila. Drug Invention Today, 2013; 5 (3): 1-7. 
Paulkumar K, Gnanajobitha G, Vanaja M, Rajeshkumar S, Malarkodi $\mathrm{C}$ and $\mathrm{G}$ Annadurai Biosynthesis of silver chloride nanoparticles using Bacillus subtilis MTCC 3053 and assessment of its antifungal activity. ISRN Nanomaterials, 2013; doi.org/10.1155/ 2013/ 317963, 1-8.

Paulkumar K, S Rajeshkumar, G Gnanajobitha, M Vanaja, C Malarkodi and G Annadurai Eco-friendly Synthesis of Silver Chloride Nanoparticles using Klebsiella planticola (MTCC 2277). International Journal of Green Chemistry and Bioprocess 2013; 3(1): 12-16.

Penga H, A Yanga, J Xiongc Green, microwave-assisted synthesis of silver nanoparticles using bamboo hemicelluloses and glucose in an aqueous medium Carbohydrate Polymers 2013; 91: 348- 355.

Pourali P, Yahyaei B Biological production of silver nanoparticles by soil isolated bacteriaand preliminary study of their cytotoxicity and cutaneous woundhealing efficiency in rat Journal of Trace Elements in Medicine and Biology 2016; 34: 22-31.

Rajeshkumar S. Synthesis of silver nanoparticles using Fresh bark of Pongamia pinnata and its antibacterial action against gram positive and gram negative pathogen Resource-Efficient Technologies, 2016; 2: 30-35.

Rajeshkumar S and C Malarkodi. In vitro antibacterial activity and mechanism of silver nanoparticles against food borne pathogens Bioinorganic Chemistry and Applications. 2014; http://dx.doi.org/10.1155/2014/581890.

Rajeshkumar S, Malarkodi C, Paulkumar K, Vanaja M, Gnanajobitha G, Annadurai G Intracellular and extracellular biosynthesis of silver nanoparticles by using marine bacteria vibrio alginolyticus. Nanoscience and Nanotechnology: An International Journal 2013; 3(1): 21-25.
Rajeshkumar S, Malarkodi C, Vanaja M, Annadurai G Anticancer and enhanced antimicrobial activity of biosynthesizd silver nanoparticles against clinical pathogens Journal of Molecular Structure, 2016; 1116; 165-173.

Rajeshkumar S, Malarkodi C, Vanaja M, , Annadurai G Anticancer and enhanced antimicrobial activity of biosynthesizd silver nanoparticles against clinical pathogens Journal of Molecular Structure 2016; 1116: 165-173.

Rajeshkumar, S. Malarkodi, C. Paulkumar, K. Vanaja, M. Gnanajobitha, G. Annadurai G Algae mediated green fabrication of silver nanoparticles and examination of its antifungal activity against clinical pathogens. International journal of Metals Volume 2014, http://dx.doi.org/10.1155/2014/692643

Zhu S, Du C, Fu Y. Fabrication and characterization of rhombic silver nanoparticles for biosensing. Optical Mater, 2009; 31:769-74.

\section{How to cite this article:}

Venkat Kumar S, Karpagambigai S, Jacquline Rosy P, Rajeshkumar S., Controlling of Disease Causing Pathogens Using Silver Nanoparticles Synthesized by One Step Green Procedure. J App Pharm Sci, 2018; 8 (01): 142-146. 